\title{
Kinetic and Energetic Aspects of Inorganic Sulphur Compound Oxidation by Thiobacillus tepidarius
}

\author{
By WEI-PING LU† AND DON P. KELLY* \\ Department of Biological Sciences, University of Warwick, Coventry CV4 7AL, UK
}

(Received 4 August 1987; revised 27 November 1987)

\begin{abstract}
Whole organisms of Thiobacillus tepidarius oxidize thiosulphate to sulphate with the obligatory formation of tetrathionate as an intermediate. Oxidation of thiosulphate to tetrathionate shows an apparent $K_{\mathrm{m}}$ of about $120 \mu \mathrm{M}$ and is relatively insensitive to FCCP (carbonyl cyanide p-trifluoromethoxyphenylhydrazone), HQNO (2-heptyl-4-hydroxyquinoline- $N$-oxide) or thiocyanate. Oxidation of tetrathionate to sulphate shows a $K_{\mathrm{m}}$ of about $27 \mu \mathrm{M}$ and is strongly inhibited by FCCP, HQNO, thiocyanate and gramicidin. Sulphite oxidation is also inhibited by FCCP and HQNO. Trithionate oxidation to sulphate occurred and showed unexplained dependence on the presence of sulphate ions. $A \rightarrow \mathrm{H}^{+} / \mathrm{O}$ quotient of about 4 for proton translocation driven by substrate oxidation was seen for each of thiosulphate, tetrathionate and sulphite. ATP synthesis coupled to thiosulphate oxidation was completely abolished by FCCP. The results obtained are consistent with the oxidation of thiosulphate (and probably trithionate) to tetrathionate in the periplasm of the cell, with HQNO-insensitive electron transport to cytochrome $c$, and with further oxidation of tetrathionate (and sulphite) to sulphate after FCCPsensitive transport to the cytoplasmic side of the membrane. The latter oxidations involve HQNO-sensitive electron transport via cytochrome $b$. Inhibition of tetrathionate metabolism by thiocyanate and gramicidin would be consistent with tetrathionate transport by a $\mathrm{S}_{4} \mathrm{O}_{6}^{2-} / 4 \mathrm{H}^{+}$ symport process. The proton translocation experiments indicate the mechanism of $\mathrm{H}^{+}$extrusion to depend on electron transfer within the quinone/cytochromes $b c$ segment of the respiratory chain, and does not involve a proton-pumping oxidase. The sulphur-compound-oxidizing system of $T$. tepidarius is shown to be quite different from that previously described for T. versutus.
\end{abstract}

\section{INTRODUCTION}

Thiobacillus tepidarius is a moderately thermophilic and obligately chemolithotrophic bacterium that has previously been shown to grow autotrophically using energy from the oxidation of thiosulphate and polythionates (Wood \& Kelly, 1985). In its growth yields on sulphur compounds and its ability to use polythionates (Wood \& Kelly, 1986; Kelly et al., 1987), it differs from the facultatively heterotrophic Thiobacillus versutus, which can grow chemolithotrophically only on thiosulphate and sulphide (Kelly \& Kuenen 1984; Mason et al. 1987). The mechanism of thiosulphate oxidation in $T$. versutus has been studied in great detail and proved to involve a periplasmic multienzyme system (Lu \& Kelly, 1983a, b, 1988a; Lu et al.,

† Present address: Department of Biology, Fudan University, Shanghai, People's Republic of China.

Abbreviations: FCCP, carbonyl cyanide p-trifluoromethoxyphenylhydrazone; HQNO, 2-heptyl-4hydroxyquinoline- $N$-oxide; TMPD, $\quad N, N, N^{\prime}, N^{\prime}$-tetramethyl-p-phenylenediamine; APS reductase, adenylylsulphate reductase. 
$1985 ; \mathrm{Lu}, 1986)$ that generates a transmembrane proton gradient by the production of protons on the periplasmic side of the cytoplasmic membrane by virtue of this enzyme-catalysed reaction

$$
\mathrm{S}_{2} \mathrm{O}_{3}^{2-}+5 \mathrm{H}_{2} \mathrm{O}=2 \mathrm{SO}_{4}^{2-}+10 \mathrm{H}^{+}+8 e^{-}
$$

This generates a $\rightarrow \mathrm{H}^{+} / \mathrm{O}$ quotient of 2.5 (Lu \& Kelly, 1988) in a periplasmic mechanism that accords with the hypothesis that transmembrane proton gradients should be generated by the oxidation in the periplasm of 'simple' substrates (Hooper \& DiSpirito, 1985).

No obligately chemolithotrophic thiobacillus has yet been analysed in the same detail as $T$. versutus and the possible universality of the periplasmic oxidation mechanism has not been tested in other thiobacilli. Similarly, no consistent and unequivocal mechanism for inorganic sulphur compound oxidation by the obligate chemolithotrophs has yet been established (Kelly, 1982, 1985).

We have analysed the oxidation kinetics of thiosulphate and other sulphur compounds by $T$. tepidarius, and related these to its response to inhibitors of phosphorylation, respiration and electron transport, with a view to establishing the possible route for sulphur compound oxidation and its coupling to energy conservation. These results, and studies on enzymic transformation of thiosulphate, trithionate and sulphite, are presented in this and the following paper. They enable us to present a mechanism for thiosulphate oxidation that is fundamentally different from that in $T$. versutus.

\section{METHODS}

Culture of organism and preparation of suspensions. Thiobacillus tepidarius (Wood \& Kelly, 1985) was grown in chemostat culture essentially as described by Wood \& Kelly (1986), except that a 21 Quickfit culture vessel with a working volume of 1.51 was used, with stirring by means of an overhead drive motor. Temperature was maintained at $44^{\circ} \mathrm{C}$ with a Churchill thermocirculator and $\mathrm{pH}$ controlled at $\mathrm{pH} 7.0$ by automatic titration with $2 \mathrm{M}-\mathrm{K}_{2} \mathrm{CO}_{3}$. The cultures were grown at dilution rates of $0 \cdot 1-0 \cdot 2 \mathrm{~h}^{-1}$ using thiosulphate $(30 \mathrm{~mm})$, trithionate or tetrathionate $(15-20 \mathrm{mM})$ as the growth-limiting substrate.

For use in respiration measurements, using the oxygen electrode cell, some experiments were done using samples of culture removed directly from the steady state chemostat and not pretreated in any way. Such suspensions contained no residual oxidizable substrate and exhibited insignificant endogenous respiratory activity. For some experiments, organisms were harvested from the culture by centrifuging at $25000 \mathrm{~g}$ for $10 \mathrm{~min}$ at $20^{\circ} \mathrm{C}$ and resuspending in $0.1 \mathrm{M}$-potassium phosphate, $\mathrm{pH} \mathrm{7.0.} \mathrm{Such} \mathrm{suspensions} \mathrm{were} \mathrm{either} \mathrm{used} \mathrm{without}$ further treatment or were recentrifuged and the organisms suspended in the same buffer for use. For experiments in which proton translocation was measured, organisms were harvested by centrifuging, washed three times at

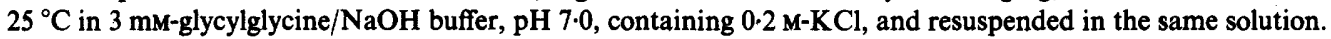

Measurement of respiration and proton translocation. Oxidation of inorganic sulphur compounds was measured in a Clark oxygen electrode cell (Rank) at $40^{\circ} \mathrm{C}$, using a working volume of $2 \mathrm{ml}$. Calculation of oxidation rates and stoichiometry was based on an oxygen content of $195 \mathrm{nmol} \mathrm{O}_{2}$ per $\mathrm{ml}$ of reaction mixture. Proton translocation was measured essentially as described previously (Lu \& Kelly 1988a), using oxygen pulse and initial rate techniques. The reaction mixture $(3 \mathrm{ml})$ in a Clark oxygen electrode cell contained 8-12 mg dry wt $T$. tepidarius, $150 \mathrm{~mm}-\mathrm{KCl}, 1.5 \mathrm{~mm}$-glycylglycine/ $\mathrm{NaOH}, 50 \mathrm{mM}-\mathrm{KSCN}$ at an initial $\mathrm{pH} 6.5$ and $40^{\circ} \mathrm{C}$. In different experiments, the following amounts of reductants were added $(\mu \mathrm{mol})$ : thiosulphate $(0.3)$; tetrathionate $(0.5)$; sulphite $(2)$; ascorbate + TMPD $(1+0 \cdot 1)$; ferrocyanide $(0 \cdot 5)$. Air-saturated $0 \cdot 15 \mathrm{M}-\mathrm{KCl}$ was assumed to contain $195 \mathrm{nmol}$ $\mathrm{O}_{2} \mathrm{ml}^{-1}$ at $40^{\circ} \mathrm{C}$. In oxygen pulse experiments, anaerobic suspensions containing the respiratory substrates were pulsed by the addition of $20 \mu \mathrm{l}$ air-saturated $0.15 \mathrm{M}-\mathrm{KCl}$, thereby providing $7.8 \mathrm{ng}$-atoms of oxygen. Proton translocation (acidification of the reaction mixture) was measured with a Russell CMAWL probe (Russell pH) on a Pye Unicam PW $9409 \mathrm{pH}$ meter and recorded on a JJCR100 potentiometric recorder (Lloyd Instruments). Full scale deflection of the recorder corresponded to a $\Delta \mathrm{pH}$ of 0.12 , and the system was calibrated by adding $1-5 \mu \mathrm{l}$ amounts of oxygen-free $10 \mathrm{mM}-\mathrm{HCl}$ to the reaction mixture under normal experimental conditions. Carbonic anhydrase was routinely omitted from these assays, as it had no effect on the proton translocation when added at $50 \mu \mathrm{g}$ per $3 \mathrm{ml}$ reaction volume. Acidification following the addition of oxygen was complete within $5 \mathrm{~s}$. The maximum concentration of translocated $\mathrm{H}^{+}$produced by an oxygen pulse was estimated by plotting the decay of the $\Delta \mathrm{pH}$ against time (as shown in Fig $6 d$ ), and extrapolating back to zero time or the time estimated to correspond to $50 \%$ reduction of the added oxygen (Mitchell \& Moyle, 1965; Scholes \& Mictchell, 1970). The $\rightarrow \mathrm{H}^{+} / \mathrm{O}$ quotient was calculated as the maximum ng-ions of $\mathrm{H}^{+}$generated divided by the $7.8 \mathrm{ng}$-atoms of oxygen added. The $\Delta \mathrm{pH}$ was halved, and identical $\rightarrow \mathrm{H} / \mathrm{O}$ quotients obtained, when $10 \mu \mathrm{l}$ (3.9 $\mathrm{ng}$-atoms $\mathrm{O}$ ) of air-saturated $0 \cdot 15 \mathrm{M}-\mathrm{KCl}$ were used, indicating $\Delta \mathrm{pH}$ to be proportional to the amount of oxygen added. 
Table 1. Oxidation of thiosulphate and tetrathionate by T. tepidarius

The results are typical of all experiments in which $T$. tepidarius was treated in the manner described.

(a) Effect of growth substrate and of centrifugation and washing on respiratory activity

\begin{tabular}{|c|c|c|c|}
\hline \multirow{2}{*}{$\begin{array}{l}\text { Growth } \\
\text { substrate }\end{array}$} & \multirow{2}{*}{$\begin{array}{c}\text { Suspension } \\
\text { used }\end{array}$} & \multicolumn{2}{|c|}{$\begin{array}{c}\text { Rate of oxidation } \\
{\left[\text { nmol } \mathrm{O}_{2} \min ^{-1}(\mathrm{mg} \text { dry wt })^{-1}\right]}\end{array}$} \\
\hline & & Thiosulphate & Tetrathionate \\
\hline $\mathrm{Na}_{2} \mathrm{~S}_{2} \mathrm{O}_{3}$ & $\begin{array}{l}\text { Whole culture } \\
\text { Centrifuged and } \\
\text { resuspended }\end{array}$ & $\begin{array}{l}390 \\
230\end{array}$ & $\begin{array}{l}180 \\
160\end{array}$ \\
\hline $\mathrm{K}_{2} \mathrm{~S}_{4} \mathrm{O}_{6}$ & $\begin{array}{l}\text { Whole culture } \\
\text { Centrifuged and } \\
\text { resuspended }\end{array}$ & $\begin{array}{l}420 \\
266\end{array}$ & $\begin{array}{l}410 \\
405\end{array}$ \\
\hline
\end{tabular}

(b) Two-phase oxidation of thiosulphate by thiosulphate-grown bacteria in whole culture samples without centrifugation

$\begin{array}{ccc}\begin{array}{l}\mathrm{Na}_{2} \mathrm{~S}_{2} \mathrm{O}_{3} \\ \text { supplied } \\ (\mu \mathrm{M})\end{array} & \overbrace{}^{\text {Phase 1 }} & \begin{array}{c}\text { Oxidation rates } \\ \left.\text { [nmol } \mathrm{Omin}_{2}^{-1}(\mathrm{mg} \mathrm{dry} \mathrm{wt})^{-1}\right]\end{array} \\ 250 & 351 & \text { Phase 2 } \\ 750 & 429 & 273 \\ & & 275\end{array}$

\begin{tabular}{|c|c|}
\hline \multicolumn{2}{|c|}{$\begin{array}{c}\text { Amount of } \mathrm{O}_{2} \text { consumed } \\
\text { in phase } 1\end{array}$} \\
\hline$\underset{\mathrm{ml}^{-1}}{\mathrm{nmol} \mathrm{O}_{2}}$ & $\begin{array}{l}\text { nmol } \mathrm{O}_{2} \text { per } \\
\mathrm{nmol} \mathrm{S} \mathrm{O}_{3}^{2-}\end{array}$ \\
\hline $\begin{array}{r}52 \\
133\end{array}$ & $\begin{array}{l}0.21 \\
0.18\end{array}$ \\
\hline
\end{tabular}

\begin{abstract}
Measurement of ATP synthesis. Organisms from thiosulphate-limited chemostat culture $\left(D 0 \cdot 2 \mathrm{~h}^{-1}\right)$ were

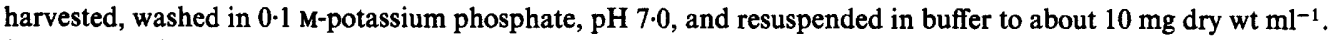
Suspensions $(1 \mathrm{ml})$ were incubated with stirring for $5 \mathrm{~min}$ at $40^{\circ} \mathrm{C}$ under air in the open chamber of an oxygen electrode cell as the reaction vessel. Reaction was initiated by adding $5 \mu \mathrm{l} 0 \cdot 1 \mathrm{M}-\mathrm{Na}_{2} \mathrm{~S}_{2} \mathrm{O}_{3}$, and terminated after $2-95 \mathrm{~s}$ by removing $0.2 \mathrm{ml}$ samples and mixing with $0.1 \mathrm{ml} 20 \%(\mathrm{v} / \mathrm{v})$ perchloric acid. Killed samples were kept at

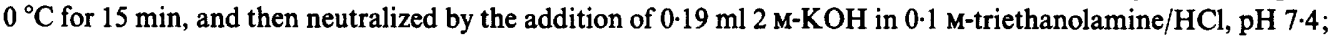
the precipitate was removed by centrifuging. ATP in the supernatant solutions was assayed by means of the commercially available 'Lumac' kit supplied by Boro Labs. Samples $(0.05 \mathrm{ml})$ were mixed with Lumic buffer $(0.45 \mathrm{ml})$ and the Lumit-SH (luciferin-luciferase mixture), with and without internal ATP standards, and the luminescence was read with a Lumac cell tester M1030. In the procedure used, a reading of 12-14 was given by $50 \mathrm{ng}$ ATP. Endogenous ATP levels in the absence of thiosulphate were also measured.

Analytical procedures. Thiosulphate and polythionates were assayed as described by Kelly et al. (1969).

Chemicals. $\mathrm{K}_{2} \mathrm{~S}_{4} \mathrm{O}_{6}$ was from Fluka. $\mathrm{Na}_{2} \mathrm{~S}_{3} \mathrm{O}_{6}$ was synthesized as described by Wood \& Kelly (1986); valinomycin, gramicidin, antimycin A, HQNO, rotenone and carbonic anhydrase were from Sigma; amytal and FCCP were from Aldrich. Reagents were from Fisons or BDH.
\end{abstract}

\title{
RESULTS
}

Thiosulphate and tetrathionate oxidation by intact cells of $T$. tepidarius

Organisms grown on either thiosulphate or tetrathionate as sole growth-limiting energy substrate could oxidize both compounds, although tetrathionate was oxidized more rapidly after growth on tetrathionate (Table $1 a$ ). Comparing rates of oxidation by organisms assayed simply by removing culture samples from the chemostat into the oxygen electrode cell with suspensions of organisms prepared by centrifuging, washing and suspending in phosphate buffer, showed that the ability to oxidize thiosulphate was decreased by the washing procedure while oxidation of tetrathionate was less affected. It was noted that material with a haem spectrum was sometimes found in the supernatant liquid from centrifuging dense cultures, indicating that loss of cytochrome-material could account for impaired thiosulphate-oxidizing ability.

The stoichiometry of substrate oxidation was consistent with the equations

$$
\begin{gathered}
\mathrm{S}_{2} \mathrm{O}_{3}^{2-}+2 \mathrm{O}_{2}+\mathrm{H}_{2} \mathrm{O}=2 \mathrm{SO}_{4}^{2-}+2 \mathrm{H}^{+} \\
\mathrm{S}_{4} \mathrm{O}_{6}^{2-}+3 \cdot 5 \mathrm{O}_{2}+3 \mathrm{H}_{2} \mathrm{O}=4 \mathrm{SO}_{4}^{2-}+6 \mathrm{H}^{+}
\end{gathered}
$$



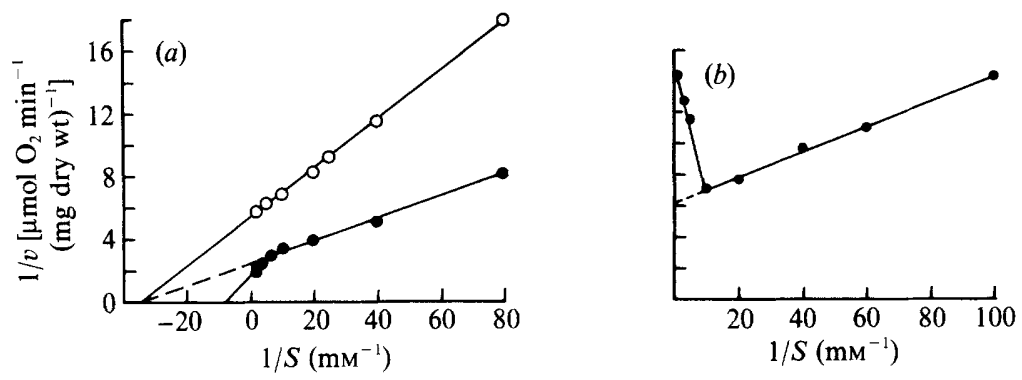

Fig. 1. Lineweaver-Burk plots of reciprocals of oxidation rates against reciprocals of concentration of $(a)$ thiosulphate $(O)$ or tetrathionate $(O)$, and $(b)$ trithionate. Fresh, uncentrifuged samples of thiosulphate-grown cultures of $T$. tepidarius $\left(0.28 \mathrm{mg} \mathrm{dry} \mathrm{wt} \mathrm{ml}^{-1}\right)$ were used for measurements of thiosulphate and trithionate oxidation. Tetrathionate oxidation was assayed using organisms $\left(1.5 \mathrm{mg}\right.$ dry $\mathrm{wt} \mathrm{ml}^{-1}$ ) that were centrifuged and resuspended in $0 \cdot 1 \mathrm{M}$-potassium phosphate, $\mathrm{pH} 7 \cdot 0 . K_{\mathrm{m}}$ values indicated by these plots were $28 \mu \mathrm{M}$ tetrathionate, $13 \mu \mathrm{M}$ trithionate and two values of 27 and $118 \mu \mathrm{M}$ for thiosulphate.

In many cases, thiosulphate oxidation by chemostat culture samples showed two phases (Table $1 b$ ). The initial fast rate accounted for about $10 \%$ of the total oxygen uptake required for equation (2) and suggested the initial conversion of thiosulphate to tetrathionate, as observed previously for batch cultures (Wood \& Kelly, 1985, 1986)

$$
2 \mathrm{~S}_{2} \mathrm{O}_{3}^{2-}+0 \cdot 5 \mathrm{O}_{2}+2 \mathrm{H}^{+}=\mathrm{S}_{4} \mathrm{O}_{6}^{2-}+\mathrm{H}_{2} \mathrm{O}
$$

Apparent $K_{\mathrm{m}}$ values for the oxidation of thiosulphate and tetrathionate (for thiosulphategrown organisms) were determined from Lineweaver-Burk plots using substrate concentrations over the range $12 \cdot 5-500 \mu \mathrm{M}$ (Fig. $1 a$ ). For tetrathionate, a single value of $28 \mu \mathrm{M}$ was found, while thiosulphate produced a biphasic plot, indicative of a $K_{\mathrm{m}}$ of $118 \mu \mathrm{M}$ for high concentrations of substrate and $27 \mu \mathrm{M}$ for concentration below $100 \mu \mathrm{M}$. Comparing thiosulphate oxidation by culture samples and washed suspensions showed a fall in $V_{\max }$ from $540 \mathrm{nmol} \mathrm{O}_{2} \mathrm{~min}^{-1}$ (mg dry wt) $)^{-1}$ in the former to 350 in the latter, but the $K_{\mathrm{m}}$ values for the latter remained at 29 and $105 \mu \mathrm{M}$. It was found that at high concentrations, thiosulphate was converted predominantly to tetrathionate, and that the $K_{\mathrm{m}}$ of $105-118 \mu \mathrm{M}$ corresponds to the phase one oxidation of thiosulphate to tetrathionate.

\section{Oxidation of trithionate and sulphite by T. tepidarius.}

Trithionate and sulphite were oxidized completely to sulphate by organisms taken from cultures grown on either thiosulphate or tetrathionate. Trithionate was found to be an autoinhibitory substrate, causing decreased rates of oxygen uptake at concentrations above $100 \mu \mathrm{M}$ (Fig. 1 b). Between 10-100 $\mu \mathrm{M}-\mathrm{Na}_{2} \mathrm{~S}_{3} \mathrm{O}_{6}$ a Lineweaver-Burk plot (Fig. $1 b$ ) indicated a $K_{\mathrm{m}}$ of $13 \mu \mathrm{M}$ with an apparent $V_{\max }$ of about $330 \mathrm{nmol} \mathrm{O} \min ^{-1}\left(\mathrm{mg}\right.$ dry wt) ${ }^{-1}$. Using organisms removed directly from a trithionate-limited chemostat, trithionate oxidation occurred at $334 \mathrm{nmol} \mathrm{O} \min ^{-1}$ (mg dry wt) ${ }^{-1}$ with $50 \mu \mathrm{M}-\mathrm{Na}_{2} \mathrm{~S}_{3} \mathrm{O}_{6}$ and at $250 \mathrm{nmol} \mathrm{min}-1$ (mg dry wt) $)^{-1}$ with $250 \mu \mathrm{M}$-trithionate. Tetrathionate and thiosulphate (at $0.5 \mathrm{mM}$ ) were both oxidized by trithionate-grown organisms at rates of 140 and $190 \mathrm{nmol} \mathrm{O}_{2} \mathrm{~min}^{-1}\left(\mathrm{mg}\right.$ dry wt) ${ }^{-1}$ respectively. Centrifuging and resuspending thiosulphate-grown organisms in phosphate buffer resulted in the loss of most of the trithionate-oxidizing activity. It was found that this loss of activity could be virtually completely restored by adding sulphate to the suspensions (Table $2 a$ ). Thus $\mathrm{Na}_{2} \mathrm{SO}_{4}$ restored activity to $27,44,60,70$ and $80 \%$ of that of the untreated culture when supplied at 5,10 , 15,20 and $25 \mathrm{~mm}$ respectively. It was also found that organisms in which activity had been restored with $\mathrm{MgSO}_{4}$ or $\mathrm{KHSO}_{4}$ did not exhibit inhibition of the restored rate by levels of trithionate seen to be inhibitory to organisms tested without removal from the growth medium (Table $2 b$ ). Chlorides could not replace sulphate as restorers of activities. 
Table 2. Loss and recovery of trithionate-oxidizing ability in T. tepidarius

Organisms from a thiosulphate-limited chemostat were assayed using either suspensions of culture $\left(0.22 \mathrm{mg}\right.$ dry $\left.\mathrm{wt} \mathrm{m} \mathrm{m}^{-1}\right)$ withdrawn directly from the chemostat, or after centrifuging, washing in $0.1 \mathrm{M}$ potassium phosphate, $\mathrm{pH} 7 \cdot 0$, and using at $0.6 \mathrm{mg} \mathrm{dry} \mathrm{wt} \mathrm{ml}^{-1}$ in the oxygen electrode cell. Oxidation rates in the presence of various supplements were measured using $(a)$ trithionate at $50 \mu \mathrm{M}$ initial concentration, or $(b)$ several trithionate concentrations. These sets of data are typical of many separate observations of the effect of centrifuging and resuspending $T$. tepidarius in the presence and absence of sulphate.

(a) Effect of pretreatment and supplements

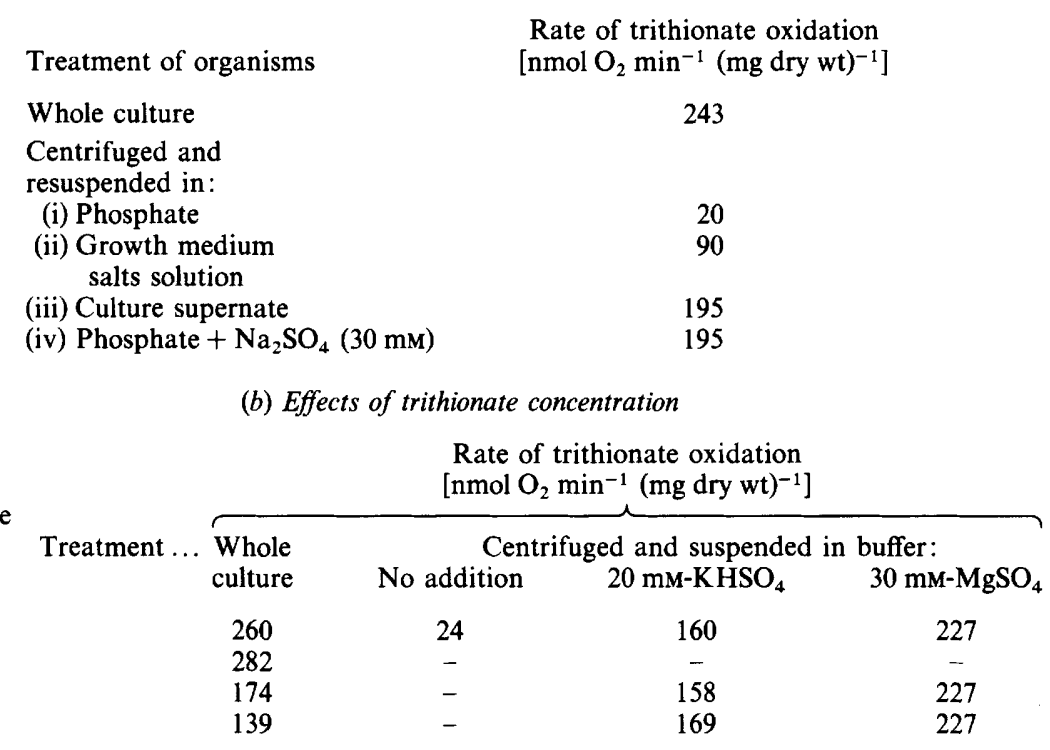

Table 3. Inhibition of the second phase of thiosulphate oxidation by FCCP

Samples of culture $\left(0.27 \mathrm{mg}\right.$ dry $\left.\mathrm{wt} \mathrm{ml}^{-1}\right)$ removed directly from a thiosulphate-limited chemostat were assayed in the oxygen electrode using $2 \mu \mathrm{M}-\mathrm{FCCP}$ added 1-2 min before thiosulphate. Results of a typical representative experiment are shown.

$\begin{array}{cclc}\begin{array}{c}\text { Thiosulphate } \\ \text { concn } \\ (\mu \mathrm{M})\end{array} & \begin{array}{c}\text { FCCP } \\ \text { added } \\ (\mu \mathrm{M})\end{array} & \overbrace{\text { nmol }}^{\begin{array}{c}\text { Total oxygen consumed at the } \\ \text { cessation of oxidation }\end{array}} \\ 100 & 0 & 202 & \text { nmol per } \mathrm{S}_{2} \mathrm{O}_{3}^{2-} \\ 50 & 2 & 12 \cdot 4 & 2 \cdot 02 \\ 100 & 2 & 24 \cdot 7 & 0 \cdot 25 \\ 250 & 2 & 68 & 0 \cdot 25 \\ & & & 0 \cdot 27\end{array}$

\section{Effect of FCCP on sulphur compound oxidation}

FCCP was a potent inhibitor of tetrathionate oxidation by $T$. tepidarius taken from a thiosulphate-limited chemostat. FCCP, added 1-2 min before tetrathionate, caused a lag of 4-6 min before a constant rate of oxygen uptake was achieved. The oxidation rate was inhibited $50 \%$ by $5 \times 10^{-8} \mathrm{M}-\mathrm{FCCP}$, using $0.27 \mathrm{mg}$ dry wt $\mathrm{ml}^{-1}$. Such a low $\mathrm{I}_{50}$ is typical of the effect of FCCP as an uncoupler of energy metabolism. Using high concentrations of thiosulphate (e.g. $0.5 \mathrm{mM}$ and above) as substrate, and thus measuring only the first phase of oxidation, FCCP was not a very effective inhibitor of oxidation, causing only 14 and $43 \%$ inhibition at 0.25 and $10 \mu \mathrm{M}$ respectively. If lower concentrations of thiosulphate were used, $2 \mu \mathrm{M}$-FCCP was seen to inhibit the second phase of oxidation completely (Table 3), resulting in the consumption of only 

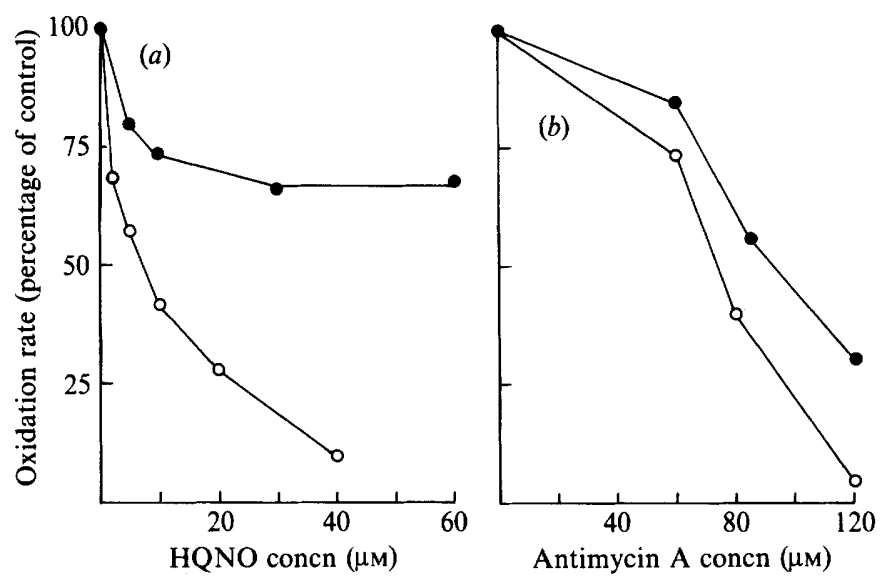

Fig. 2. Inhibition of oxidation of thiosulphate $(O)$ and tetrathionate $(O)$ by $(a)$ HQNO and $(b)$ antimycin A. Washed suspensions of $T$. tepidarius $\left(0.5 \mathrm{mg} \mathrm{dry} \mathrm{wt} \mathrm{ml}^{-1}\right)$ were preincubated with inhibitors for $5 \mathrm{~min}$ before adding substrates.

$0.25 \mathrm{~mol} \mathrm{O}_{2}$ per thiosulphate provided. When the $K_{\mathrm{m}}$ for thiosulphate was determined for 25-250 $\mu \mathrm{M}$-thiosulphate in the presence of $1 \mu \mathrm{M}$-FCCP a single line was obtained in a Lineweaver-Burk plot, indicating a $K_{\mathrm{m}}$ of $125 \mu \mathrm{M}$, typical of the first phase of oxidation, and indicating no tetrathionate oxidation component. The effect of a range of concentrations of FCCP $(0.125-2 \mu \mathrm{M})$ on the oxidation of thiosulphate $(250 \mu \mathrm{M})$ was examined: the first phase of oxidation proceeded at a rate of $327 \pm 40 \mathrm{nmol} \mathrm{O}_{2} \min ^{-1}$ (mg dry wt) $)^{-1}$ for all FCCP concentrations $(0-2 \mu \mathrm{M})$, with $92 \%$ of the control rate being seen at $2 \mu \mathrm{M}-\mathrm{FCCP}$. The rate of the second phase of oxidation fell from $303 \mathrm{nmol} \mathrm{O}_{2} \mathrm{~min}^{-1} \mathrm{mg}^{-1}$ in the control and with $0.125 \mu \mathrm{M}$ FCCP to 277 with 0.25 or $0.4 \mu \mathrm{M}$-FCCP and to 43,30 and 25 with FCCP at $0.5,0.8$ and $2 \mu \mathrm{M}$, representing $86-92 \%$ inhibition. This degree of inhibition was the same as for the oxidation of tetrathionate. The formation of tetrathionate during the first phase of oxidation in the presence of FCCP was demonstrated by chemical analysis. In another experiment, $T$. tepidarius suspended in phosphate buffer $(0.8 \mathrm{mg} \text { dry wt ml })^{-1}$ oxidized thiosulphate at an initial rate of $195 \mathrm{nmol} \mathrm{O}_{2} \min ^{-1} \mathrm{mg}^{-1}$ in the absence of FCCP, but was stimulated to $316 \mathrm{nmol}$ $\mathrm{O}_{2} \mathrm{~min}^{-1} \mathrm{mg}^{-1}$ by $4 \mu \mathrm{M}$-FCCP, which reduced the second phase rate to $6 \mathrm{nmol} \mathrm{min}^{-1} \mathrm{mg}^{-1}$. Under these conditions, analysis after $50 \mathrm{~s}$ incubation (with approximately $2 \mathrm{mM}$-thiosulphate) showed the consumption of $211 \mathrm{nmol} \mathrm{O}_{2} \mathrm{ml}^{-1}$ and the presence of $440 \mathrm{nmol} \mathrm{S}_{4} \mathrm{O}_{6}^{2-}$ and $800 \mathrm{nmol} \mathrm{S}_{2} \mathrm{O}_{3}^{2-} \mathrm{ml}^{-1}$. The amount of oxygen predicted by equation (4) to be required to produce $440 \mathrm{nmol} \mathrm{S} \mathrm{O}_{6}^{2-}$ from thiosulphate is $220 \mathrm{nmol}$.

Trithionate oxidation by whole culture samples taken from a trithionate-limited chemostat was also inhibited by FCCP: oxygen uptake rates fell by 46,67 and $100 \%$ in the presence of 0.5 , 1.25 and $5 \mu \mathrm{M}$-FCCP respectively. FCCP at $1 \mu \mathrm{M}$ inhibited trithionate oxidation by thiosulphate-grown organisms by $78 \%$. Sulphite and tetrathionate oxidation were comparably sensitive to FCCP, with FCCP at $5 \times 10^{-8} \mathrm{M}$ causing $50 \%$ inhibition of sulphite oxidation.

\section{Inhibition of sulphur compound oxidation by $H Q N O$ and antimycin $A$}

Washed cell suspensions of $T$. tepidarius from cultures grown on thiosulphate or tetrathionate showed marked inhibition of tetrathionate oxidation by HQNO (Fig. 2a). Thiosulphate oxidation (initial rate) was less sensitive (Fig. $2 a$ ), although at $150 \mu \mathrm{M}-\mathrm{HQNO}$ the initial oxidation rate was depressed by $80 \%$. Trithionate oxidation was depressed by 25,38 and $75 \%$ by HQNO at 4, 9.5 and $19 \mu \mathrm{M}$ respectively. Sulphite oxidation was inhibited with sensitivity similar to that of tetrathionate, the rate being depressed $90 \%$ by $30 \mu \mathrm{M}-\mathrm{HQNO}$. 


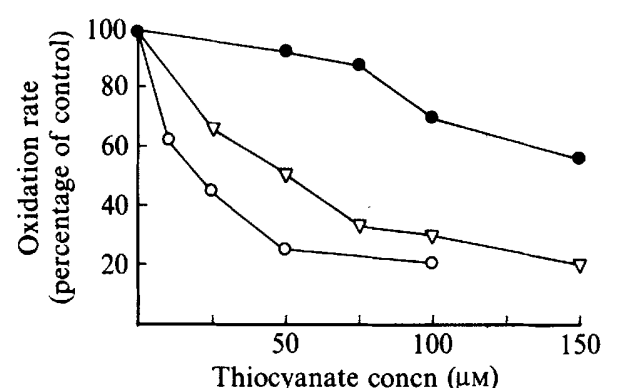

Fig. 3

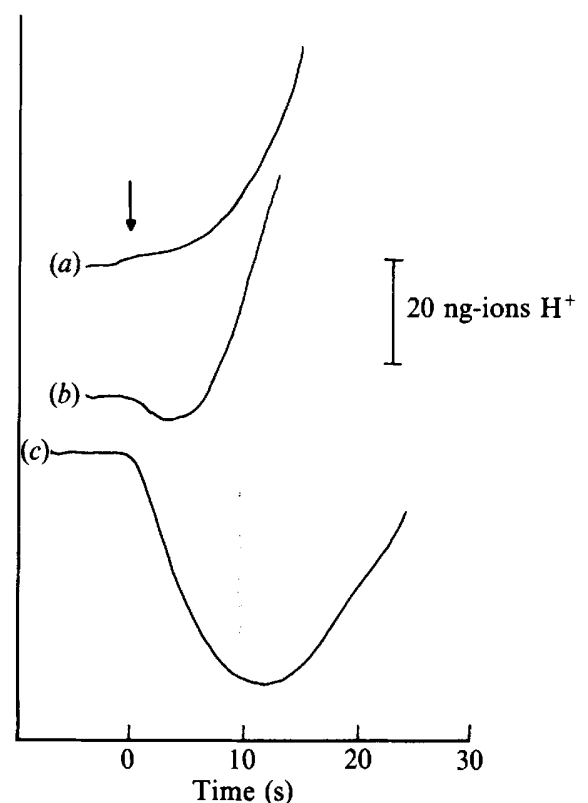

Fig. 4

Fig. 3. Inhibition of oxidation of thiosulphate $(O, \nabla)$ and tetrathionate $(O)$ by thiocyanate. Conditions were as in Fig. 2, with 0.5 min preincubation with thiocyanate. Inhibition of the first phase $(\odot)$ and second phase $(\nabla)$ of thiosulphate oxidation were both measured (see text).

Fig. 4. Initial alkalization of suspensions of $T$. tepidarius following addition of thiosulphate. Suspensions $(3 \mathrm{ml}$ ) prepared for measurement of proton translocation by the initial rate techniques (see Methods) were stirred aerobically and thiosulphate added at zero time (arrow) to give the following initial concentrations $(\mu \mathrm{M}):(a) 33 ;(b) 67 ;(c) 100$. Relative alkalization and acidification are indicated by the bar, which represents concentration changes of $20 \mathrm{ng}$-ions $\mathrm{H}^{+}$in a $3 \mathrm{ml}$ reaction volume.

Antimycin A inhibited both thiosulphate and tetrathionate oxidation, although the latter was more sensitive (Fig. 2b). The inhibitory concentration range was somewhat high $(50 \%$ inhibition at 75-90 $\mu \mathrm{M}$ ), possibly indicating that uptake into the cell was slow.

In contrast with $\mathrm{HQNO}$ and antimycin $\mathrm{A}$, the oxidation of thiosulphate and tetrathionate was not significantly inhibited by $250 \mu \mathrm{M}$-rotenone $(10-15 \%)$ or $2.5 \mathrm{mM}$-amytal $(0-5 \%)$.

\section{Inhibition of sulphur compound oxidation by thiocyanate and gramicidin}

The first phase of thiosulphate oxidation (to tetrathionate) was only slightly affected by thiocyanate, but tetrathionate oxidation and the second phase of thiosulphate oxidation were severely inhibited (Fig. 3).

Gramicidin inhibited tetrathionate oxidation by 50 and $59 \%$ at 25 and $100 \mu \mathrm{M}$. Partially additive inhibition was seen in the presence of $25 \mathrm{mM}$-thiocyanate ( $55 \%$ inhibition) and $25 \mu \mathrm{M}$ gramicidin $(70 \%$ combined inhibition).

Insignificant inhibition of tetrathionate oxidation was produced by nigericin or valinomycin $+\mathrm{K}^{+}$even after preincubation for $20 \mathrm{~min}$, possibly indicating failure of these compounds to gain access to the cytoplasmic membrane.

\section{Effect of thiosulphate concentration on the initial accumulation of tetrathionate during oxidation}

Since the oxidation of thiosulphate to tetrathionate consumes one proton per thiosulphate ion oxidized (equation 4), the production of small amounts of tetrathionate could be demonstrated by measuring instantaneous changes in the $\mathrm{pH}$ of lightly buffered suspensions of $T$. tepidarius (see Methods) following addition of thiosulphate. Using $100 \mu \mathrm{M}$-thiosulphate, initial alkalization was significant and was only balanced by $\mathrm{H}^{+}$extrusion after about $30 \mathrm{~s}$ (Fig. 4). A smaller, 


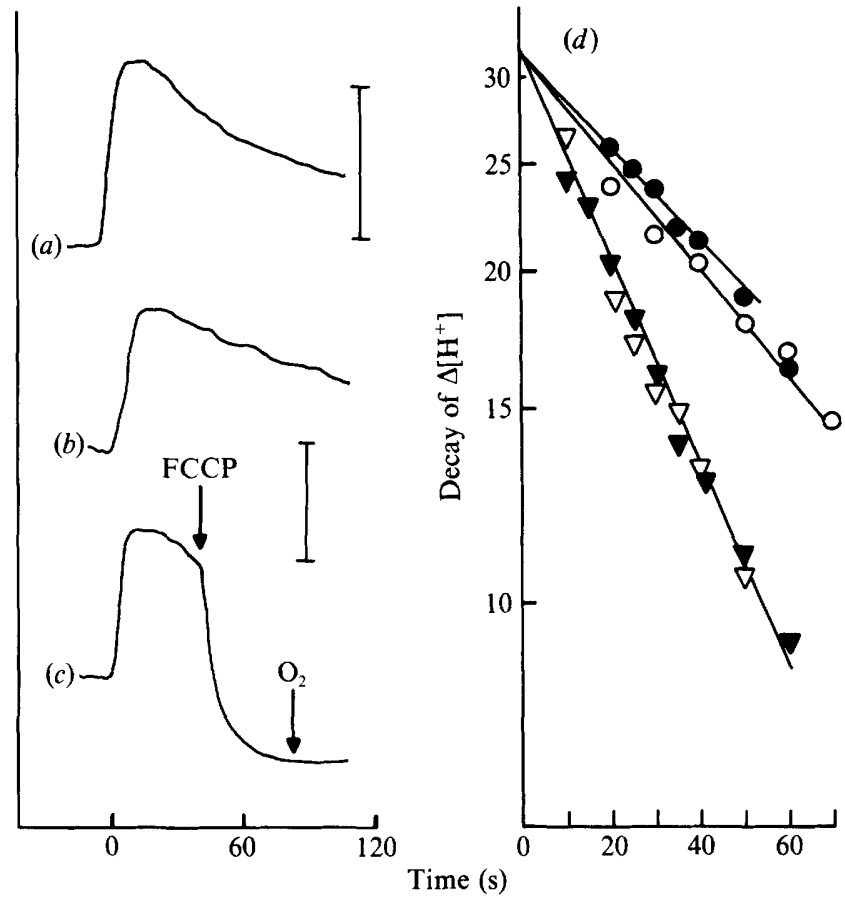

Fig. 5. Proton translocation linked to oxidation of thiosulphate, tetrathionate and sulphite by $T$. tepidarius. Changes in $\mathrm{H}^{+}$concentration $(\mathrm{pH})$ were measured by the oxygen pulse technique (see Methods), using $(a)$ thiosulphate or $(b)$ tetrathionate as reductant, and adding $7.8 \mathrm{ng}$-atoms $\mathrm{O}$ at zero time on the traces. The effect of adding FCCP $(0.5 \mu \mathrm{M})$ on tetrathionate-dependent proton translocation, and of addition of a second oxygen pulse, are shown in trace (c). The bars represent $20 \mathrm{ng}-$ ions $\mathrm{H}^{+}$for traces $(a)$ and $(b),(c)$ respectively. The $\rightarrow \mathrm{H}^{+} / \mathrm{O}$ quotient was determined by plotting exponential decay of concentration of the translocated protons $(d)$ for thiosulphate in the absence $(\nabla)$ and presence $(O)$ of rotenone $(30 \mu \mathrm{M})$, and for tetrathionate $(O)$ and sulphite $(\nabla)$, both in the presence of rotenone $(30 \mu \mathrm{M})$.

transient alkalization accompanied the oxidation of $67 \mu \mathrm{M}$-thiosulphate, but at $33 \mu \mathrm{M}$, no alkalization preceded the progressive acidification of the suspension that resulted from oxidation to sulphate (Fig. 4). The alkalization being observed only with higher concentrations of thiosulphate is consistent with the differences in $K_{\mathrm{m}}$ and $V_{\max }$ for the oxidation of thiosulphate to tetrathionate (Fig. $1 \mathrm{a} ; 118 \mu \mathrm{M}$ and $385 \mathrm{nmol} \mathrm{O}_{2} \mathrm{~min}^{-1} \mathrm{mg}^{-1}$ ) and of tetrathionate to sulphate (Fig. $1 a ; 28 \mu \mathrm{M}$ and $182 \mathrm{nmol} \mathrm{min}^{-1} \mathrm{mg}^{-1}$ ), by which the rate of tetrathionate production would exceed its further oxidation only at a higher initial concentration of thiosulphate.

\section{Respiration-dependent proton translocation by $T$. tepidarius}

Anaerobic suspensions of $T$. tepidarius were pulsed, as described in Methods, with a small amount of oxygen and proton translocation from the organisms was determined by measurement of $\mathrm{pH}$ change. In the absence of substrate there was no proton translocation, which was consistent with the absence of aerobic endogenous respiration in organisms harvested from chemostat culture. In the presence of thiosulphate, tetrathionate (Fig. $5 a, b)$ or sulphite there was instantaneous $\mathrm{H}^{+}$ejection, followed by a slow decay of the $\Delta \mathrm{pH}$ (Fig. $5 a, b$ ). Essentially identical results were obtained over the $\mathrm{pH}$ range $6 \cdot 2-7 \cdot 0$ and with thiocyanate concentrations of $30-65 \mathrm{mM}$. Addition of $0.5 \mu \mathrm{M}-\mathrm{FCCP}$ resulted in immediate and complete dissipation of the tetrathionate-dependent $\Delta \mathrm{pH}$ (Fig. $5 \mathrm{c}$ ). Prior incubation for up to $1.5 \mathrm{~h}$ with valinomycin $\left(10 \mu \mathrm{g} \mathrm{ml}^{-1}\right)$ resulted in poor respiration-linked $\mathrm{H}^{+}$translocation. Prior addition of FCCP $(0.5 \mu \mathrm{M})$ or HQNO $(25 \mu \mathrm{M})$ inhibited $\mathrm{H}^{+}$translocation, but amytal $(1.6 \mathrm{mM})$ and rotenone $(135 \mu \mathrm{M})$ had no effect, which was consistent with their lack of effect on substrate oxidation. 
Table 4. $\rightarrow H^{+} / O$ quotients for the oxidation of various reductants by $T$. tepidarius

\begin{tabular}{|c|c|c|c|c|}
\hline Substrate & $\begin{array}{l}\text { Rotenone } \\
\text { added } \\
(\mu \mathrm{M})\end{array}$ & $\rightarrow \mathrm{H}^{+} / \mathrm{O}^{*}$ & $\begin{array}{c}t_{1 / 2}{ }^{\dagger} \\
(\mathrm{s})\end{array}$ & $\begin{array}{c}\text { Rate of substrate } \\
\text { oxidation } \\
{\left[\mathrm{nmol} \text { min }(\mathrm{mg} \mathrm{dry} \mathrm{wt})^{-1}\right]}\end{array}$ \\
\hline Thiosulphate & 0 & $4.08 \pm 0.37(7)$ & 35 & 65 \\
\hline Thiosulphate & 30 & $4 \cdot 10 \pm 0.07(3)$ & 70 & 60 \\
\hline Tetrathionate & 30 & $3.92 \pm 0.31(6)$ & 65 & 15 \\
\hline Sulphite & 30 & $3.79 \pm 0.39(8)$ & 35 & 11 \\
\hline Ascorbate/TMPD & 0 & $1 \cdot 1$ & - & 70 \\
\hline Ferrocyanide & 0 & 0 & - & 5 \\
\hline
\end{tabular}

\footnotetext{
* Respiration-linked proton translocation was measured by the oxygen pulse technique as described in Methods; $\rightarrow \mathrm{H}^{+} / \mathrm{O}$ was calculated as described in the text and in the legend to Fig. 6. Mean values ( \pm SDs) are given for the number of separate determinations shown in parentheses.

$\dagger$ Mean half-time for decay of $\Delta \mathrm{pH}$ in a number of separate determinations. See Fig. 7.
}

The decay of the $\Delta \mathrm{pH}$ showed first order kinetics with a half-time $\left(t_{1 / 2}\right)$ for thiosulphatedependent $\mathrm{H}^{+}$translocation of about $35 \mathrm{~s}$ in the absence of rotenone and about $75 \mathrm{~s}$ in its presence (Fig. $5 d$ ). Decay of $\Delta \mathrm{pH}$ produced by sulphite was the same as that with thiosulphate in the absence of rotenone; that with tetrathionate in the presence of rotenone was the same as for thiosulphate under the same conditions (Fig. $5 d$ ). The maximum concentrations of protons resulting from the oxygen pulse were determined by plotting the $\Delta \mathrm{pH}$ exponential decay data from numerous replicate determinations (as shown in Fig. $5 d$ ) and extrapolating back to the maximum value. Classically, this value is taken at the time at which half the added oxygen has been reduced (Scholes \& Mitchell, 1970). The initial rate of oxygen uptake during thiosulphate and tetrathionate oxidation showed complete reduction of the $7.8 \mathrm{ng}$-atoms of $\mathrm{O}$ added in all the experiments to occur in 0.3 to $1.4 \mathrm{~s}$. Since the $t_{1 / 2}$ values for the $\mathrm{H}^{+}$decay always exceeded $30 \mathrm{~s}$ this meant that extrapolation to zero time for all the $\Delta \mathrm{pH}$ decay data gave as good a value for the maximum $\Delta \mathrm{pH}$ as could be obtained (Scholes \& Mitchell, 1970). Dividing the maximum $\mathrm{H}^{+}$ value so obtained by the $7.8 \mathrm{ng}$-atoms of $\mathrm{O}$ added gave $\rightarrow \mathrm{H}^{+} / \mathrm{O}$ quotients that did not differ significantly from a common value of 4.0 for thiosulphate, tetrathionate or sulphite in the presence or absence of rotenone (Fig. 5d, Table 4). Calculating the $\rightarrow \mathrm{H}^{+} / \mathrm{O}$ value for thiosulphate (in the absence of rotenone) for extrapolated $\mathrm{H}^{+}$concentrations at 0 or $2 \mathrm{~s}$ gave $4.08 \pm 0.37$ and $4.01 \pm 0.30$ respectively showing that the rapid decay of $\Delta \mathrm{pH}$ introduced no significant error. Similarly with tetrathionate (at an oxidation rate of $7.8 \mathrm{ng}$-atoms $\mathrm{O}$ reduced in $1.4 \mathrm{~s}$ ), the $\rightarrow \mathrm{H}^{+} / \mathrm{O}$ values at 0 and $5 \mathrm{~s}$ were $3.92 \pm 0.31$ and $3.81 \pm 0.33$.

$\rightarrow \mathrm{H}^{+} / \mathrm{O}$ quotients were also estimated for the rapid oxidation of ascorbate/TMPD and rather slow oxidation of ferrocyanide by suspensions of $T$. tepidarius (Table 4). The $\rightarrow \mathrm{H}^{+} / \mathrm{O}$ quotient for ascorbate/TMPD-dependent proton translocation was also estimated from measurements of the initial rates of $\mathrm{H}^{+}$production and $\mathrm{O}_{2}$ uptake. This gave a value of 0.86 .

\section{Effect of FCCP on ATP synthesis by T. tepidarius}

FCCP was shown above to inhibit tetrathionate oxidation very strongly and to block only the second phase of thiosulphate oxidation when added to the organisms before the substrate. When it was added after the substrate it was less immediately effective and took measurable time to inhibit sulphur compound oxidation. Thus $2 \cdot 5 \mu \mathrm{M}$-FCCP added 4 min after tetrathionate did not affect the oxidation in the subsequent $2 \mathrm{~min}$. Thiosulphate oxidation was unaffected within $1 \mathrm{~min}$ by $2.5 \mu \mathrm{M}$-FCCP added $45 \mathrm{~s}$ after thiosulphate addition, and the thiosulphate oxidation rate was still $80-100 \%$ of the control $40 \mathrm{~s}$ after adding $5 \mu \mathrm{M}$-FCCP. It was thus possible to test the effect of thiosulphate-dependent ATP synthesis under conditions in which substrate oxidation was minimally affected.

Following addition of thiosulphate to a cell suspension, the ATP content of the organisms rose about eightfold within $2 \mathrm{~s}$ (Fig. 6), decaying slowly to a high steady state value. Prior additions of FCCP completely prevented ATP synthesis. If FCCP was added 5 or $60 \mathrm{~s}$ after thiosulphate, the ATP content fell very rapidly by up to $60 \%$. 


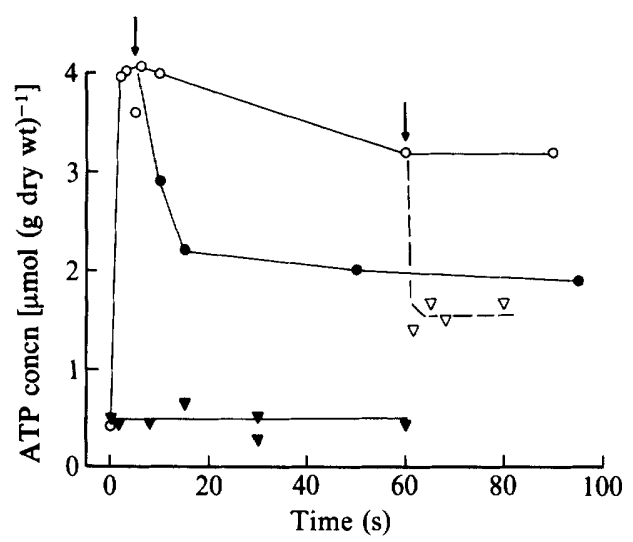

Fig. 6. ATP synthesis by $T$. tepidarius following addition of thiosulphate, and inhibition by FCCP. Aerobic suspensions of organisms $\left(10 \mathrm{mg}^{\mathrm{dry}} \mathrm{wt} \mathrm{ml}^{-1}\right)$ harvested from thiosulphate-limited chemostat culture and suspended in $0 \cdot 1 \mathrm{M}$-potassium phosphate buffer, $\mathrm{pH} 7 \cdot 0$, were incubated at $40^{\circ} \mathrm{C}$ and given

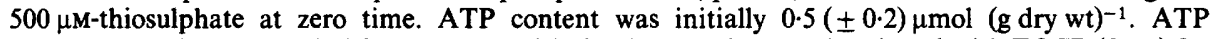
concentration in controls $(O)$ is compared with that in organisms preincubated with FCCP $(5 \mu \mathrm{M})$ for 2 min prior to thiosulphate addition $(\nabla)$; the effect is shown of adding $1.25 \mu \mathrm{M}-\mathrm{FCCP}$ after $5 \mathrm{~s}$ (arrow; ) or $5 \mu \mathrm{M}$-FCCP after $60 \mathrm{~s}$ (arrow; $\nabla$ ).

\section{DISCUSSION}

Our observations on thiosulphate oxidation by $T$. tepidarius show clearly that the initial reaction is the oxidation of thiosulphate to tetrathionate with a $K_{\mathrm{m}}$ of about $120 \mu \mathrm{M}$. The subsequent oxidation of tetrathionate to sulphate proceeds with an overall $K_{\mathrm{m}}$ of about $27 \mu \mathrm{M}$. The observations that $(a)$ the oxidation of thiosulphate to tetrathionate was insensitive to concentrations of FCCP that could completely inhibit oxidation of tetrathionate and sulphite, and $(b)$ the first phase of thiosulphate oxidation was only slightly affected by HQNO, while the oxidation of tetrathionate and sulphite was strongly inhibited, suggest that the initial oxidation of thiosulphate to tetrathionate could be effected by a periplasmically located oxidase system, coupling electron transport to cytochrome $c$. In contrast, tetrathionate and sulphite oxidations are indicated to require the membrane to be in an energized state and their oxidation is consequently abolished by FCCP. This means that tetrathionate and sulphite probably have to cross the cytoplasmic membrane in order to undergo further metabolism either in the cytoplasm or at least on the inner surface of the cytoplasmic membrane. The powerful inhibition of tetrathionate and sulphite oxidation by HQNO (and antimycin A) suggests that the ubiquinone, cytochrome $b /$ cytochrome $c$ link in the electron transport chain is involved in the oxidation of these substrates, but not in that of thiosulphate to tetrathionate. This supports the view that tetrathionate and sulphite oxidation occur on the cytoplasmic side of the membrane and couple electron transport directly to ubiquinone/cytochrome $b$ on the inner surface of the cytoplasmic membrane. The intermediate sensitivity of trithionate oxidation to FCCP and HQNO suggest that tetrathionate or sulphite could be essential free intermediates in its metabolism, possibly requiring its initial reduction or hydrolysis to thiosulphate as proposed for T. neapolitanus (Trudinger, 1964; Okuzumi, 1966; Kelly \& Syrett, 1966). The proposal that thiosulphate oxidation to tetrathionate occurs outside the cytoplasmic membrane is also consistent with the early observation by Trudinger (1965) that $T$. neapolitanus (which also readily oxidizes tetrathionate) appeared to be impermeable to thiosulphate under anaerobic conditions in which no thiosulphate oxidation could occur. Trudinger (1965) also proposed that the S-S bond of thiosulphate remained intact prior to active transport of the molecule into the cell, as would be the case both in it and in T. tepidarius if the chemical species actually transported across the membrane were tetrathionate. 
Tetrathionate oxidation was also inhibited by gramicidin and thiocyanate. These inhibitors respectively dissipate the transmembrane $\Delta \psi$ and $\Delta \mathrm{pH}$, showing that both $\Delta \psi$ and $\Delta \mathrm{pH}$ are involved in tetrathionate transport across the membrane. An implication of this observation is that more than $2 \mathrm{H}^{+}$would be required for cotransport with tetrathionate into the cytoplasm, as both the proton gradient and membrane potential appear to be the driving force. It is possible therefore that tetrathionate uptake is a symport process requiring three or more $\mathrm{H}^{+}$per tetrathionate ion transported. This possibility has not yet been further investigated.

A striking finding was the marked loss of ability of the bacteria to oxidize thiosulphate or trithionate if they were subjected to centrifugation and washing prior to use, while tetrathionate oxidation was virtually unaffected. The loss of activity suggested that a loosely bound or periplasmic component was essential for thiosulphate (and trithionate) oxidation, such as a thiosulphate oxidizing enzyme or even cytochrome $c$. The latter is a possibility as the supernatant medium from the cultures was frequently shown to contain a $c$-type haem pigment. Loss of trithionate-oxidizing ability was at least partly restored by sulphate: this has no adequate explanation to date but suggests that an initial step in trithionate metabolism is sulphateactivated as discussed in the following paper ( $\mathrm{Lu} \& \mathrm{Kelly}, 1988 \mathrm{~b}$ ). The observation that organisms grown on any one of thiosulphate, trithionate or tetrathionate exhibited constitutive ability to oxidize all three compounds suggests that there is an early common intermediate in the metabolism of these substrates.

The demonstration of a $\rightarrow \mathrm{H}^{+} / \mathrm{O}$ quotient of about 4 for proton translocation driven by the oxidation of thiosulphate, tetrathionate and sulphite is in contrast with the values of about 2.5 for thiosulphate and 2 for sulphite found in $T$. versutus ( $\mathrm{Lu} \& \mathrm{Kelly}, 1988 a$ ). The latter values are consistent with complete oxidation of the substrates in the periplasm, and the generation of a $\Delta \mathrm{pH}$ exclusively by the electrons produced from the substrate oxidation reactions (Hooper \& DiSpirito, 1985). It is thus apparent that $T$. tepidarius generates a $\Delta \mathrm{pH}$ by the active translocation (extrusion) of protons across the cytoplasmic membrane, dependent on the oxidation of tetrathionate (or other intermediates) on the cytoplasmic side of the membrane. The demonstration that the oxidation of ascorbate/TMPD or ferrocyanide by $T$. tepidarius gave $\rightarrow \mathrm{H}^{+} / \mathrm{O}$ quotients of 1 or 0 suggests that the reoxidation of cytochrome $c$ by the cytochrome oxidase in this organism is unlikely to be coupled to proton translocation. This contrasts with the ability of mitochondrial and Paracoccus denitrificans cytochrome $a a_{3}$ to catalyse proton translocation (Wikström et al., 1981; Hatefi, 1985; Harold, 1986). Consequently, all proton translocation driven by sulphur compound oxidation must be dependent on electron transfer within the quinone/cytochromes $b c$ segment of the respiratory system, producing a ratio of $4 \mathrm{H}^{+} / 2 e^{-}$as discussed by Wikström et al. (1981) and Hatefi (1985). The stoichiometry of the ATP synthase with regard to the number of protons translocated for each ATP synthesis is uncertain, with $3 \mathrm{H}^{+} /$ATP being favoured but 2 or $4 \mathrm{H}^{+} /$ATP also being possible (Harold, 1986). In $T$. versutus the approximate $\mathrm{ATP} / \mathrm{O}$ and $\rightarrow \mathrm{H}^{+} / \mathrm{O}$ quotients were 1 and 2.5 respectively for thiosulphate oxidation ( $\mathrm{Lu} \& \mathrm{Kelly}, 1983 a, 1988 a$ ), thereby indicating a ratio of $2-3 \mathrm{H}^{+} / \mathrm{ATP}$. Extrapolating this to $T$. tepidarius would indicate a $\mathrm{P} / \mathrm{O}$ ratio possibly as high as 2 for the $\rightarrow \mathrm{H}^{+} / \mathrm{O}$ quotient of 4. This would be consistent with the transfer of electrons from tetrathionate oxidation through cytochrome $b$ to oxygen, and with the higher growth yield of $T$. tepidarius than $T$. versutus seen in chemostat culture on thiosulphate (Kelly et al., 1987). Alternatively, the superior growth yield of $T$. tepidarius might be attributable largely to the entry of electrons into the respiratory chain at the level of ubiquinone/cytochrome $b$, and the energetic saving thus achieved in the respiratory energy-dependent reduction of $\mathrm{NAD}^{+}$using reduced cytochrome $b$ or $c$ as reductant which operates in the thiobacilli (Kelly, 1978, 1982).

$T$. versutus apparently lacks APS reductase (adenylyl sulphate reductase) and is unable to generate ATP by substrate level phosphorylation. APS reductase has not been shown in $T$. tepidarius and the complete abolition of ATP synthesis produced in $T$. tepidarius by concentrations of FCCP not affecting thiosulphate oxidation could indicate that there is no role for APS reductase or substrate level phosphorylation in sulphur compound oxidation by T. tepidarius. 
These observations demonstrate that the mechanism of inorganic sulphur compound oxidation in T. tepidarius is apparently quite different from the periplasmic multienzyme system found in $T$. versutus (Lu \& Kelly, 1983b; Lu et al., 1985; Kelly, 1985; Lu, 1986). The seemingly obligatory role of tetrathionate as an intermediate in thiosulphate oxidation by $T$. tepidarius and the constitutive ability to oxidize thiosulphate, trithionate and tetrathionate, irrespective of growth substrate, are in complete contrast to $T$. versutus, which cannot metabolize polythionates. Such observations may be indicative of convergent evolutionary origins for the sulphur-oxidizing mechanisms in the taxonomically and physiologically distinct thiobacilli such as the obligately chemolithotrophic and thermophilic $T$. tepidarius and the facultatively heterotrophic, mesophilic T. versutus.

We wish to acknowledge financial support from the Science Funds of the Chinese Academy of Science, the International Foundation for Science (Sweden), the President's Fund of the Society for General Microbiology, and Fudan University, Shanghai. We are grateful to Drs R. K. Poole and D. E. Griffiths for useful discussion.

\section{REFERENCES}

HAROLD, F. M. (1986). The Vital Force: a Study of Bioenergetics, pp. 231-246. New York: W. H. Freeman.

HATEFI, Y. (1985). The mitochondrial electron transport and oxidative phosphorylation system. Annual Review of Biochemistry 54, 1015-1069.

HOOPER, A. B. \& DiSpirito, A. A. (1985). In bacteria which grow on simple reductants, generation of a proton gradient involves extracytoplasmic oxidation of substrate. Microbiological Reviews 49, 140-157.

KELLY, D. P. (1978). Bioenergetics of chemolithotrophic bacteria. In Companion to Microbiology, pp. 363-386. Edited by A. T. Bull \& P. M. Meadow. London: Longman.

KeLly, D. P. (1982). Biochemistry of the chemolithotrophic oxidation of inorganic sulphur. Philosophical Transactions of the Royal Society B298, 499-528.

KELLY, D. P. (1985). Physiology of the thiobacilli: elucidating the sulphur oxidation pathway. Microbiological Sciences 2, 105-109.

Kelly, D. P. \& Kuenen, J. G. (1984). Ecology of the colourless sulphur bacteria. In Aspects of Microbial Metabolism and Ecology, pp. 211-240. Edited by G. A. Codd. Orlando: Academic Press.

Kelly, D. P. \& SYRETT, P. J. (1966). [ ${ }^{35}$ S]Thiosulphate oxidation by Thiobacillus strain C. Biochemical Journal 98, 537-545.

Kelly, D. P., Chambers, L. A. \& Trudinger, P. A. (1969). Cyanolysis and spectrophotometric estimation of trithionate in mixture with thiosulfate and tetrathionate. Analytical Chemistry 41, 898-901.

Kelly, D. P., Mason, J. \& WoOD, A. P. (1987). Energy metabolism in chemolithotrophs. In Microbial Growth on $C_{1}$ Compounds, pp. 186-194. Edited by H. W. van Verseveld \& J. A. Duine. Dordrecht: Martinus Nijhoff.

LU, W.-P. (1986). A periplasmic location for the thiosulphate-oxidizing multi-enzyme system from Thiobacillus versutus. FEMS Microbiology Letters 34, 313-317.

LU, W.-P. \& Kelly, D. P. (1983a). Thiosulphate oxidation, electron transport and phosphorylation in cell-free systems from Thiobacillus A2. Journal of General Microbiology 129, 1661-1671.

LU, W.-P. \& KELLY, D. P. (1983b). Partial purification of a thiosulphate-oxidizing system from Thiobacillus A2. Journal of General Microbiology 129, 1673-1681.
LU, W.-P., Swoboda, B. E. P. \& Kelly, D. P. (1985). Properties of the thiosulphate-oxidizing multienzyme system from Thiobacillus versutus. Biochimica et biophysica acta 828, 116-122.

LU, W.-P. \& KELLY, D. P. (1988a). Respiration-driven proton translocation in Thiobacillus versutus and the role of the periplasmic thiosulphate-oxidizing enzyme system. Archives of Microbiology 149, 297-302.

LU, W.-P. \& Kelly, D. P. (1988b). Cellular location and partial purification of 'thiosulphate-oxidizing enzyme' and 'trithionate hydrolyase' from Thiobacillus tepidarius. Journal of General Microbiology 134, 877-885.

Mason, J., Kelly, D. P. \& Wood, A. P. (1987). Chemolithotrophic and autotrophic growth of Thermothrix thiopara and some thiobacilli on thiosulphate and polythionates, and a reassessment of the growth yields of $T$. thiopara in chemostat culture. Journal of General Microbiology 133, 1249-1256.

Mitchell, P. \& MOYLE, J. (1965). Stoichiometry of proton translocation through the respiratory chain and adenosine triphosphatase systems of rat liver mitochondria. Nature, London 208, 147.

OKuzumi, M. (1966). Reduction of trithionate by Thiobacillus thiooxidans. Agricultural and Biological Chemistry 30, 713-716.

SCHOles, P. \& Mitchell, P. (1970). Respirationdriven proton translocation in Micrococcus denitrificans. European Journal of Biochemistry 1, 309-323.

TRUDINGER, P. A. (1964). The metabolism of trithionate by Thiobacillus X. Australian Journal of Biological Sciences 17, 459-468.

TRUDINGER, P. A. (1965). On the permeability of Thiobacillus neapolitanus to thiosulphate. Australian Journal of Biological Sciences 18, 563-568.

Wikström, M., KRAB, K. \& SARASTE, M. (1981). Proton-translocating cytochrome complexes. Annual Review of Biochemistry 50, 623-655.

Wood, A. P. \& Kelly, D. P. (1985). Physiological characteristics of a new thermophilic, obligately chemolithotrophic Thiobacillus species, Thiobacillus tepidarius. International Journal of Systematic Bacteriology 35, 434-437.

Wood, A. P. \& Kelly, D. P. (1986). Chemolithotrophic metabolism of the newly isolated moderately thermophilic, obligately autotrophic Thiobacillus tepidarius. Archives of Microbiology 144, 71-77. 